\title{
$O$ ambulatório de saúde mental na rede de atenção psicossocial: reflexóes sobre a clínica e a expansão das políticas de atenção primária
}

| ${ }^{1}$ Issa Damous, ${ }^{2}$ Hilana Erlich |

Resumo: O movimento de Reforma Psiquiátrica e as recentes diretrizes no âmbito da Atenção Primária em Saúde redirecionam o modelo de assistência em saúde mental no Brasil e viabilizam grandes conquistas. Nesse contexto, este artigo aborda o ambulatório de saúde mental com o objetivo de afirmá-lo enquanto um dispositivo fundamental e potente na rede de atenção psicossocial. Tendo a clínica como eixo condutor, a discussão empreendida segue principalmente contribuiçôes teóricas de referência sobre os fundamentos do campo da atenção psicossocial, as políticas públicas de saúde e de saúde mental, além de considerar os aportes teóricoclínicos de autores atravessados pela psicanálise e inseridos no campo da saúde mental, assim como a longa experiência das autoras nesse campo.

Destaca-se então a dimensão clínica concernente ao ambulatório, creditando-se o vigor potente desse dispositivo a certo modo de exercê-la, às diferentes modalidades ofertadas, à organização dos serviços e ao acolhimento e acompanhamento de determinada clientela. Trata-se de sustentar finalmente que, a partir de uma atitude desperta para a clínica, um ambulatório de saúde mental potente em uma rede de atenção psicossocial promove efetivamente o almejado trabalho voltado para o território e, portanto, para a desinstitucionalização.

> Palavras-chave: saúde mental; atenção psicossocial; ambulatório; clínica.
${ }^{1}$ Departamento de Psicologia, Universidade Federal Fluminense - UFF/PURO. Rio das Ostras-RJ, Brasil (issa@infolink.com.br).

2 Superintendência de Saúde Mental, Secretaria Municipal de Saúde. Rio de Janeiro-RJ, Brasil (hilana.erlich@gmail.com).
Recebido em: 16/05/2017 Aprovado em: 08/07/2017 


\section{O ambulatório de saúde mental em pauta}

A menção ao ambulatório de saúde mental nos dias de hoje parece entoar uma melodia ultrapassada. De fato, pouco se ouve a respeito do trabalho desenvolvido nestes dispositivos. Paira no ar certo silêncio, por vezes uma má impressão e talvez mesmo um desconhecimento a seu respeito. Fala-se muito dos Centros de Atenção Psicossocial (CAPS), da Estratégia de Saúde da Família (ESF), dos hospitais, de matriciamento. Mas, e os ambulatórios de saúde mental?

A reordenação de uma rede de serviços substitutivos ao hospital psiquiátrico advindos com o movimento da Reforma Psiquiátrica sempre incluiu os ambulatórios, que, pelo menos nos últimos doze anos, apareceram nesse cenário. Particularmente no Rio de Janeiro, nesse período, irromperam algumas interrogaçôes, entre elas, o lugar e a função do profissional psicólogo nos ambulatórios. Em número reduzido, esses profissionais estavam, em sua maioria, inseridos em programas de saúde, como o de tabagismo, hipertensão, diabetes, HIV. Era urgente então reformular o trabalho neste equipamento fundamentalmente pela ótica clínica. Somente a partir daí seria possível deslocar tais profissionais para uma clínica ampliada, prevendo que qualquer sujeito em sofrimento, independente do diagnóstico médico, faixa etária, sintoma, gênero e mesmo psicopatologia, seria acolhido no âmbito da saúde mental.

A mudança implementada com a inserção dos psicólogos dentro dos ambulatórios representou um grande avanço, implicando a chegada de muitos pacientes antes desassistidos, ou mal assistidos, cujo comprometimento psíquico reverberava sérios prejuízos na vida cotidiana. $\mathrm{O}$ reconhecimento da importância deste trabalho levou ao aumento de contrataçôes de recursos humanos, embora ainda insuficiente. No mesmo movimento, colocou-se em questão o modo de fazer psiquiatria nos ambulatórios, até então, como especialidade isolada, marcada por uma clínica cujo acento recaía ainda na farmacoterapia.

Podemos reconhecer nesse sentido modificaçóes que trouxeram para o contexto ambulatorial uma vitalidade significativa. Foram estabelecidas reuniōes de equipe regulares, fomentou-se a aproximação e interlocução de profissionais de saúde mental, muitas vezes operando juntos ao acolhimento nos moldes do grupo de recepção. Ampliou-se ainda o grupo de trabalhadores deste campo para além de psiquiatras e psicólogos, disponibilizando-se em algumas 
unidades enfermeiros, assistentes sociais, terapeutas ocupacionais. Nessa mesma

perspectiva, devem ser destacadas as discussóes promovidas nos fóruns de saúde mental nas áreas programáticas da cidade. Elas ressaltaram definitivamente o ambulatório de saúde mental como dispositivo clínico legítimo e potente na rede de cuidados, não apenas aos casos considerados leves e moderados, mas também aos graves. Esse redimensionamento do trabalho foi de fato um marco. Desse contexto, reuniram-se as novas diretrizes no documento intitulado Recomendaçóes sobre atendimento em saúde mental na rede básica (BRASIL, 2005).

Desde então, a despeito do fomento supracitado, esse mesmo dispositivo vem aparecendo, em geral, de modo pouco expressivo na rede de atenção psicossocial. Essa pouca visibilidade dos ambulatórios de saúde mental, mesmo diante da expansão das políticas de atenção primária e o subsequente avanço da clínica via Estratégia de Saúde da Família chama-nos a atenção.

De fato, o ambulatório de saúde mental parece estar pouco presente nas discussóes tanto no âmbito micro da clínica, que perpassa os dispositivos da rede de atenção psicossocial, quanto no macro, no que tange à política pública de saúde. Esta ausência se expressa nitidamente na Portaria 3.088/11, que institui a Rede de Atenção Psicossocial (RAPS), na qual o ambulatório foi excluído do quadro de dispositivos de cuidados. Na medida em que se verifica na prática a importância estratégica do lugar e função do ambulatório de saúde mental, acreditamos ser fundamental retomar a discussáo sobre este equipamento, com vistas a problematizar a falta de investimento a ele no cenário atual das politicas publicas de saúde e suas consequências, o que entendemos ser de grande prejuízo para o desenho da rede e os processos do cuidar.

Faz-se necessário, portanto, reconhecer e afirmar a importância do a mbulatório no discurso e no cenário da rede de saúde mental como um dos equipamentos fundamentais para sua articulação, bem como para o acolhimento do público e seu atendimento.

Vale lembrar que mesmo após críticas e questionamentos ferrenhos sobre o ambulatório no início dos anos 1990, os grupos de recepção irromperam como possibilidade estratégica de reimpulsionar o recurso ambulatorial de saúde mental como dispositivo clínico. O Cadernos IPUB no 17, publicado em 2000, é inteiramente dedicado a contribuiçóes acerca da clínica da recepção, evidenciando uma preocupação importante com o trabalho realizado nos diferentes 
ambulatórios, não se restringindo a eles, mas se propagando por diversos outros serviços, como os próprios CAPS.

Nosso objetivo então é convidar a uma reflexão acerca do ambulatório de saúde mental na atualidade. No percurso traçado, discutimos o momento de novos atravessamentos advindos das políticas públicas de saúde, sobretudo em face à expansão das políticas de atenção primária, sem recuar diante dos questionamentos inerentes à conjuntura específica da clínica nesse dispositivo. $\mathrm{O}$ que nos move nesta direção é o reconhecimento da potência que o trabalho clínico em saúde mental tem no espaço ambulatorial, seja no âmbito das psicoterapias ou mesmo da psicanálise, mas, de qualquer maneira, demarcando o favorecimento a mudanças de posicionamento subjetivo em relação ao sofrimento psíquico, o que permite sustentá-lo efetivamente como uma ferramenta dentro da rede de atenção psicossocial.

E por que não arriscar dizer que qualquer montagem, em sua particularidade geográfica e arquitetônica, pode ser potente, se privilegiar em sua lógica de cuidado um determinado modo de fazer clínica que enfim promova novos arranjos subjetivos.

\section{Algumas referências sobre o campo da saúde mental no Brasil}

Desde o nascimento da psiquiatria com Pinel, no século XVIII, o tratamento em saúde mental foi basicamente hospitalocêntrico, médico-centrado e voltado para a remissão de sintomas, num contexto de premissas disciplinares sustentadas, sobretudo, por medidas de vigilância e controle. Após a Segunda Guerra Mundial, movimentos de Reforma Psiquiátrica irromperam em diferentes países, especialmente a partir de uma mobilização da sociedade em prol dos direitos humanos. Com efeito, os horrores ocasionados com a Guerra, incluindo a semelhança das instituiçôes psiquiátricas com os campos de concentração, exigiam muitas modificações. Era então importante colocar em questão os fundamentos daquele modelo de assistência psiquiátrica. No Brasil, o período de reabertura política no final da década de 1970 foi um grande marco para impulsionar o redirecionamento do modelo de assistência em saúde mental no país em direção ao que se convenciona denominar atualmente de o paradigma da atenção psicossocial (AMARANTE, 2007). 
Embalado por um amplo processo de Reforma Psiquiátrica, o Brasil dos anos 1970, na sua conjuntura sociopolítica, viu os ambulatórios como uma atraente proposta de incremento da assistência em saúde mental até então pautada praticamente apenas no hospital psiquiátrico. Na verdade, a proposta ambulatorial de assistência já vinha sendo pleiteada no país como diretriz para a assistência médica como um todo por setores progressistas preocupados com o que despontava como crise político-financeira no âmbito sanitário (SILVA FILHO, 2000).

Todavia, a disseminação dos ambulatórios como uma das respostas à crise que afetava a assistência em saúde mental não tarda a mostrar sua ineficácia, sendo uma medida logo bastante questionada. Ocorre que, no início dos anos 1990, a ambulatorizaçáo, sobretudo da psiquiatria, é acusada de cronificar uma clientela em tratamentos sustentados por consultas esparsas e repetição burocrática de prescriçóes medicamentosas. Esse quadro, de fato, não alterava de forma consistente as frequentes (re)internaçóes psiquiátricas e ainda reafirmava os fundamentos do modelo tradicional, estendendo o alcance do mandato de controle social outorgado à psiquiatria (SILVA FILHO, 2000). Sendo assim, se por cerca de duas décadas, o ambulatório de saúde mental ganha espaço na assistência, logo a seguir, não são poucas as críticas feitas à expansão de uma rede ambulatorial em saúde mental em razão de promover a cronificação da clientela e induzir à farmacodependência (ALVES; GULJOR, 2005). Com o mandato de responder a uma crise hospitalocêntrica, os ambulatórios, portanto, de partida, estavam fadados a náo corresponderem ao resultado esperado, posto que sua lógica de assistência não alterasse o direcionamento vigente até então, apenas o perpetuasse.

Concomitante às primeiras críticas à proposta ambulatorial de assistência, avança no Brasil a formalização das políticas públicas de saúde nos moldes do Sistema Único de Saúde, o SUS, modelo que vinha sendo elaborado ao longo dos anos e que sustenta a base da política sanitária brasileira definida em 1988 na Constituição Federal. A política do SUS é regulamentada em 1990 norteada por princípios que somente têm sentido na relação entre si. São eles: a universalidade (acesso para todos), a equidade (justa igualdade) e a integralidade (prevenção, tratamento e promoção da saúde em conjunto com o indivíduo, com a comunidade, e de modo contínuo). Com essa diretriz clara de política pública, trata-se fundamentalmente de enfatizar no território nacional a cidadania e a inclusão social: a saúde como direito de todos, acessível 
a todos e em todos os níveis de complexidade. E já no intuito de fazer avançar e qualificar o SUS, a Política Nacional de Humanização (PNH) é então criada pelo Ministério da Saúde, em 2003.

Desse modo, o campo da saúde mental também deve estar compatibilizado com as bases das políticas públicas de saúde, favorecendo conquistas com suas diretrizes que reescrevem as práticas segregadoras, violentas, excludentes e de total descaso que vigoravam até então como características do modelo hospitalocêntrico de assistência. A partir daí, intervenções em clínicas públicas e conveniadas são possíveis, assim como fóruns de discussão e produção teórica, criaçáo de rede de cuidados, algumas portarias fundamentais, como a $106^{1} \mathrm{e}$ a $336^{2}$, a aprovaçáo da Lei $10.216^{3}$ e da Lei $10.708^{4}$, a III e a IV Conferência Nacional de Saúde Mental, entre muitas outras conquistas que amparam o processo de desinstitucionalização. Com isso, o modelo de cuidado supóe agora um viés ampliado, pautado em liberdade, integralidade, enfrentamento dos riscos, consideração dos direitos e fomento a singularidade e autonomia possíveis. Esses aspectos são compreendidos como condição efetiva para o exercício da inclusão e da cidadania, assim como para empreender a tâo almejada desinstitucionalização no campo da saúde mental.

No bojo da Reforma Psiquiátrica, e com inspiração no movimento italiano, bastante acolhido no Brasil, a "verdadeira desinstitucionalização" é referida ao "processo prático-crítico que reorienta instituições e serviços, energias e saberes, estratégias e intervençôes em direção a este tão diferente objeto" (ROTELLI, 1990, p. 91), a saber, um objeto que não é a doença mental, mas "a existênciasofrimento do sujeito e sua relação com o corpo social” (ROTELLI, 1990, p. 90).

Nesse sentido, o objeto da saúde mental é complexo em sua própria definição. Esta perspectiva implica, em contrapartida, uma rede de cuidados que também não seja fixa e que esteja em permanente reinvenção, a fim de acompanhar este tâo complexo objeto. Se o que emerge no campo de ação é complexo, então a resposta também deve ser complexa e em todos os níveis de assistência.

Certamente, toda essa conjuntura diz respeito aos diferentes e múltiplos dispositivos de assistência de cada território, que estão para além do campo da saúde mental e mesmo da saúde, incluindo recursos do desenvolvimento social, trabalho, lazer, entre outros. Entrelaçados por suas complexas relaçóes que convidam muito mais à corresponsabilização do que a transferência de 
responsabilidades, estes dispositivos trabalham numa lógica intersetorial caracterizada por uma "rede de iniciativas múltiplas" (PITTA, 2001, p. 278). Tais iniciativas constituem uma rede de atenção que agencia cuidados, na qual cada profissional e cada serviço pode contribuir com sua especificidade para o campo comum do cuidado àquele que sofre.

De fato, faz-se necessário implementar um cuidado ampliado em saúde mental na perspectiva da atenção psicossocial, considerando-se que se trata de sujeitos de direitos, singulares, com uma autonomia possível (ALVES; GULJOR, 2005). O CAPS aparece nesse cenário como a base do processo de redirecionamento do modelo tradicional de assistência em saúde mental no Brasil, constituindo-se como a referência primordial dos serviços substitutivos e da lógica de cuidado, que, fazendo valer suas açóes no território, exerce seu poder em todas as direçôes (ELIA, 2005).

Num primeiro momento, a lógica CAPS de cuidado pode ter causado a falsa impressão de que o mal que havia a ser combatido no âmbito da Reforma Psiquiátrica consistia na própria exclusão da loucura (ELIA, 2005). Desse modo, em contrapartida aos riscos de medicalização e de patologização, os CAPS comportam uma perspectiva cidadâ, inclusiva, reabilitadora e social, evidenciando claramente efeitos terapêuticos. Todavia, "a doença mental existe como positividade fenomênica e estrutural, que não é mero resultado de processos político-sociais de exclusão", alerta Elia (2005, p. 58). Nesse sentido, o cuidado inclusivo deve ser perpassado pela dimensão clínica. E não pode abrir mão dela!

Partindo desse princípio, tomamos a clínica aqui como soberana, como aquela que sustenta e orienta uma direção de tratamento e à qual estão remetidas as açôes com o usuário. Desse modo, o CAPS, assim como o ambulatório e os demais dispositivos de saúde mental, tem um potencial clínico legítimo na rede de cuidados ampliados e inclusivos.

\section{O papel do ambulatório na rede de atençáo psicossocial}

Situamos então o ambulatório de saúde mental como um dispositivo clínico legítimo e potente no campo da atenção psicossocial. Contudo, em tempos nos quais ouvimos e nos lançamos em propostas de novos desenhos da assistência, com a ampliação de investimentos na cobertura da atenção primária através, principalmente, da Estratégia de Saúde da Família (ESF), faz-se mister revisitar o 
ambulatório seguindo como balizas os pressupostos que sustentam atualmente o campo complexo da atenção psicossocial. Nesse sentido, parece-nos imprescindível reafirmar a especificidade do ambulatório de saúde mental, a partir do seu lugar, função e possibilidades de trabalho efetivamente sustentáveis.

Os diferentes dispositivos de saúde são ordenados numa rede de cuidados que contempla níveis variados de complexidade. Isto implica um alinhamento entre o grau, ou nível de comprometimento do que se apresenta, e as respostas oferecidas. De partida, o ambulatório em geral se caracteriza basicamente pela possibilidade do ir e vir, ou seja, seu modo de funcionamento implica certa regularidade de atendimentos previamente agendados, em diferentes especialidades clínicas. Isto significa que a clientela assistida no ambulatório pode suportar minimamente um tempo de espera em relação ao horário de funcionamento da unidade, ao primeiro atendimento e consultas subsequentes, embora possam, por vezes, contar com prontos atendimentos.

Cabe destacar que o cuidado em saúde encontra-se ordenado no SUS em níveis de atenção, que são de básica, média e alta complexidade, nos quais estão situados os níveis da atenção primária, secundária, terciaria e quaternária. Este desenho da assistência prevê que em cada nível de atenção estejam circunscritas certas açôes, definindo, assim, determinadas práticas. No nível primário, as açooes compreendem promoção, prevenção e proteção à saúde, tendo no Programa Saúde da Família sua principal estratégia de organização da atenção básica. No nível secundário, a prática é pautada pelo atendimento e tratamento por especialidades. O nível terciário contempla as internaçóes/hospitalizaçóes e o quaternário envolve as práticas de reabilitação. Esses níveis de atenção em saúde definem uma prática, o que é diferente da categoria na qual uma Unidade de Saúde se inscreve, como policlínicas, clínicas da família, UPAs, Centros Municipais de Saúde (CMSs), Hospitais. O ambulatório de saúde mental, especificamente, está situado no nível de atenção secundária, uma vez que oferta assistência especializada, ainda que possa localizar-se fisicamente em uma Unidade de Atenção Primária.

No que diz respeito então ao ambulatório de saúde mental, trata-se de uma estrutura situada no nível de atenção secundária, oferecendo basicamente atendimento psicoterápico individual ou em grupo a todas as faixas etárias e desempenhando uma função complementar à atenção básica e aos CAPS ao atuar, principalmente no caso de unidades mistas, como referência no matriciamento 
da rede de atenção em saúde mental e na capacitação de recursos humanos.

A relevância em localizar-se num nível secundário de atenção faz com que o ambulatório de saúde mental seja, na rede de cuidados, o dispositivo que oferta um cuidado especializado não previsto na atenção básica, de modo continuado e com possibilidade resolutiva. É importante assinalar que, ainda que os CAPS também estejam na atenção secundária, contando com muitos especialistas, a clientela de ambos é distinta, tornando, assim, cada qual um equipamento de saúde a ser indicado conforme a avaliação da demanda. Desse modo, ainda que o profissional inserido no ambulatório esteja capacitado para o enfrentamento de risco clínico e psicossocial, o mandato desse dispositivo, atravessado pelas políticas públicas, constitui-se de maneira limitada para acompanhar a clientela com graves transtornos psíquicos que necessitem de uma intensividade de cuidado, muitas vezes numa frequência diária. Tais pacientes se beneficiariam mais de uma lógica CAPS de cuidado. Além disso, a oferta do ambulatório não se dirige ao acompanhamento de crises agudas, emergenciais, ainda que a partir dele estas situaçôes possam ser recebidas e daí disparadas algumas açôes: "Os centros e postos de saúde recebem uma clientela que sofre do corpo e da vida mas suporta o ir e vir cotidiano para se tratar no ambulatório", como bem aponta Figueiredo (1997, p. 172). Dessa forma, aqueles que têm certo grau de autonomia e suportam aguardar até retornar podem se beneficiar desse tipo de dispositivo como lugar para tratamento na rede.

A função do ambulatório de saúde mental se articula, assim, fundamentalmente ao lugar secundário que o dispositivo ocupa na rede, oferecendo, no que lhe é particular, tratamento psicoterápico para quem se encontra em situação de sofrimento psíquico, levando em conta, sobretudo, o viés clínico, cujo modo de exercício passaremos a explorar. Sobre isto, certos norteadores como acesso, acolhimento e acompanhamento (SCHMIDT; FIGUEIREDO, 2009) perpassam o cotidiano de diferentes serviços, sendo as vicissitudes desses eixos entrelaçadas com o modo de funcionamento do serviço e a clientela a que se destina. Nesse sentido, o que deve orientar o direcionamento de um paciente acolhido em um serviço de saúde mental é balizado pelo diagnóstico clínico-situacional, contemplando-se aqui o diagnóstico psicopatológico e o risco psicossocial, que deve igualmente perpassar a história de vida e o modo como anteriormente o paciente lidou com outras situaçóes difíceis. Sendo assim, questôes como grau 
de sofrimento psíquico, prejuízo da vida cotidiana, rede de apoio e necessidade de frequência do acompanhamento podem ser consideradas mais pertinentes do que apenas a estrutura psíquica ou psicopatologia. É necessário, contudo, um refinamento da clínica no sentido de decantar a demanda e, assim, esclarecer o que está em jogo antes de finalmente oferecer alguma resposta.

No ambulatório de saúde mental, é possível desenvolver essa clínica cuja direção inclui o sujeito no centro do cuidado. Consideramos nesse sentido a subjetividade daquele que adoece e sofre sob um viés potencializador de seu repertório simbólico, fazendo-o no contexto da clínica. Valorizamos, assim, o modo como o sujeito se apresenta, a relação que ele estabelece consigo mesmo e com o seu entorno, a sua contratualidade, o que ele pode dizer de seu sofrimento, o que pode repensar a partir daí. Para além de um enfoque aprisionado no binômio queixa-conduta, que remontaria ao modelo tradicional de assistência e reforçaria uma tendência à patologização da vida, ainda apostamos numa clínica que singulariza. Entendemos que dessa maneira o sofrimento pode ser recolhido e articulado à história de vida, possibilitando, enfim, a partir de um trabalho, alguma mudança subjetiva. Todo esse trabalho tem início na porta de entrada do serviço e pode se desdobrar em um acompanhamento no próprio serviço ou em outro, num encaminhamento para fora do campo da saúde ou mesmo em um esvaziamento ou uma resolutividade da queixa que se apresenta.

Tratando-se, portanto, do ambulatório de saúde mental, o desdobramento feito na porta de entrada destinado ao acompanhamento no próprio serviço tem como especificidade a psicoterapia, individual ou em grupo. De fato, essa modalidade de atendimento caracteriza e particulariza este espaço, não sendo uma especialidade da ESF e tampouco se destinando a uma clientela que o faria no CAPS. Com efeito, por mais que o trabalho no ambulatório hoje comporte grupos com pais e responsáveis por crianças e adolescentes, reunióes de equipe, supervisão, matriciamento, visita domiciliar, grupos de recepção, grupos de apoio/suporte/ reflexão, a especificidade do ambulatório consiste, de fato, em um trabalho de escuta e fala continuado, com perspectiva de alta e conduzido pelo especialista.

O ambulatório tem então justificada sua potencialidade na dinâmica de um trabalho que requer tempo e que se destina a uma determinada clientela intermediária à ESF e ao CAPS, porém nem sempre excludentes a eles, na medida em que alguns pacientes podem ser acompanhados pela ESF e, concomitantemente, 
realizar psicoterapia no ambulatório, bem como outros podem estar referidos ao CAPS e também utilizar o ambulatório. Desse modo, não temos o intuito de afirmar que o ambulatório desempenha uma clínica específica, mas que desempenha uma clínica que interessa à rede e que por isso tem nela um lugar legítimo do qual não se pode prescindir se o que é almejado, em última instância, é potencializar sujeitos. Enquanto lugar de atendimento especializado, para fins de tratamento continuado e voltado para determinada clientela, o ambulatório de saúde mental deve ser visto como de grande relevância para a saúde pública.

Certamente, a dinâmica a que nos referimos é sustentada por certo modo de operar a clínica em saúde mental, o que pressupóe, no mínimo, um despertar para a clínica...

\section{O ambulatório e a clínica}

A clínica, de acordo com Foucault (2001), nasce no seio da Medicina. Oriunda do termo grego Kliné (DORON; PAROT, 1998), que significa leito, o ato clínico inaugura-se no movimento de inclinação do médico na direção do paciente, para observá-lo e, a partir daí, produzir um saber. A clínica, em sua origem, teve como prevalência o olhar médico, um olhar marcadamente soberano diante do qual a doença deveria emergir como fato. Posteriormente, verificamos uma dilatação do espaço da clínica, que se desdobrando noutros campos, para além da medicina, passou a incluir o movimento de fala e escuta, operando aí uma torçáo, na qual passa a ser reconhecido o doente atravessado por sua subjetividade. Nesse novo contexto, o acento recai no dizer do paciente; naturalmente, então, aquele que o escuta pode desempenhar uma função de investigar, de buscar conexões e, assim, redefinir as balizas de sua terapêutica. De tal modo, para além de inclinar-se sobre o paciente e conhecer a verdade sobre sua doença, acreditamos que seja necessário um despertar daquele que trata para o que do singular, do novo pode emergir no encontro com cada um, numa aposta de também despertá-lo para o trabalho, incluindo-o aí não como objeto de cuidados, mas como sujeito responsável por seu dito.

A ideia de um despertar para a clínica faz referência a um viés de trabalho que não reduz as manifestações da subjetividade a diagnósticos pautados pelos manuais, como DSMs e CIDs, nos quais o sofrimento é muitas vezes cristalizado num código científico que, ao universalizar os sujeitos, faz perder de vista o que 
é da ordem do singular. As classificações diagnósticas propostas nesses manuais resumem a formação dos sintomas aos modos diferenciados de apresentação de transtornos que os compóem. Trata-se da orientação psiquiátrica contemporânea que, fundamentada no modelo da medicina moderna, seguindo cada vez mais exacerbadamente os parâmetros científicos, excluiu a expressão singular de cada sintoma e em cada sujeito, ejetando a subjetividade do campo clínico. $\mathrm{O}$ advento da ciência moderna na verdade inaugura a possibilidade de incluir no campo do humano a sua subjetividade, trazendo uma nova dimensão para a experiência clínica, uma ampliação do raio de cuidado, do olhar. Entretanto, no mesmo golpe a exclui de seu campo de operação (Cf. ERLICH; ALBERTI, 2008). Como consequência deste ato no que tange à clínica médica, o conhecimento científico é usado a serviço de uma decodificação da problemática apresentada, sendo a fala, ou construçấo de saber do doente em geral, desconsiderada perante o saber da ciência. Desse modo, a prática da clínica médica deixa de se debruçar sobre a singularidade de cada caso em seu processo de adoecimento e, a fim de atender à imposiçáo de classificação da ciência, passa a se especializar cada vez mais nos detalhes das patologias.

Nesse contexto, no que diz respeito à psiquiatria prevalente na atualidade, os sinais e sintomas parecem servir exclusivamente como índice para identificação de algum dos transtornos mentais catalogados no cardápio classificatório dos diagnósticos, desconsiderando o sintoma como manifestação subjetiva e particular. Do universal ao singular, a clínica de que falamos prioriza o sintoma em sua dimensão singular sem descartar a referência aos diagnósticos, e, no entanto, sem sobrepujá-los aos próprios elementos que os compóem e que, mesmo em seu universal, são particularizados em cada paciente, se guardarmos a perspectiva de ser o sintoma uma marca de cada sujeito, a melhor forma que encontrou para se conduzir na vida.

Tomando-se como exemplo a depressão enquanto uma categoria diagnóstica psiquiátrica inserida no grupo dos transtornos de humor, verifica-se que seus ditames são frequentemente sustentados por manuais que prezam por descriçôes clínicas e diretrizes diagnósticas sem pretensão de vínculo teórico. O texto de introdução da CID-10 deixa clara esta posição:

Estas descrições e diretrizes não contêm implicaçôes teóricas e não pretendem ser proposiçôes completas acerca do estágio atual de conhecimento dos transtornos. Elas são simplesmente um conjunto de sintomas e comentários sobre os quais houve uma 
concordância por parte de um grande número de conselheiros e consultores em muitos diferentes países como sendo uma base razoável para definir os limites de categorias na classificação de transtornos mentais (OMS, 1992, p. 2).

Essas diretrizes reúnem consensualmente os conjuntos de sintomas e comentários que orientam a definição dos diferentes quadros psicopatológicos. Na CID-10 (OMS, 1992), especificamente, o diagnóstico de depressão é considerado um episódio ou um transtorno recorrente do humor, podendo manifestar-se de modo leve, moderado ou grave, e devendo reunir sintomas como o humor deprimido, a perda de interesse e prazer, a redução de energia, a fadiga e a diminuição generalizada na atividade. Podem ocorrer concomitantemente a essas manifestaçôes sintomáticas alteraçôes no sono e no apetite, redução da concentração e da atenção, assim como da autoestima e da autoconfiança, ideias de culpa e de inutilidade, pessimismo em relação ao futuro e ainda ideias ou atos autolesivos, incluindo o suicídio.

Contudo, é importante notar que até a psiquiatria moderna ganhar força, muitas reformulaçôes se sucederam desde as primeiras indicaçóes quanto aos humores, na época clássica, para circunscrever o que então consistia na melancolia. $\mathrm{Na}$ verdade, muitos debates foram travados quanto à questão etiológica dos quadros clínicos até que os manuais classificatórios tentassem realizar uma síntese possível entre diferentes perspectivas. É questionável, no entanto, se a ausência de teorização nesses manuais não seria um preço alto demais a ser pago em nome da almejada síntese. Esse questionamento é bastante pertinente diante da conjuntura atual, "sem precedente", segundo Fédida (2009, p. 159), no que diz respeito à depressão ser tomada sumariamente por seus signos, servindo rapidamente como alvo para prescrições medicamentosas enquanto a clínica parece ser abolida.

Uma abertura nesse sentido pôde, felizmente, se dar noutras clínicas, como as que priorizam a fala, pois através dela pode emergir legitimamente o saber sobre si e sua verdade, jamais reduzíveis a qualquer manual diagnóstico. Isto ajuda a pensar, por exemplo, que um paciente com o diagnóstico de depressão, compensado medicamentosamente, se necessário for, pode ainda ter muito a dizer sobre seu sofrimento e precisar de tempo, espaço e disponibilidade de escuta para realizar o trabalho subjetivo de que necessita.

Sendo assim, propomos retomar a clínica que se exerce no ambulatório de saúde mental nos dias de hoje como uma experiência que possa incluir a percepção 
e o deixar-se afetar não somente pelo que se apresenta na superfície do sujeito, a queixa ou os sintomas, mas que considere a sua subjetividade, sempre singular. Tal abertura, colocada desde o primeiro encontro com um profissional que desta faça uso, é o que permite dar o norte a cada caso.

$\mathrm{O}$ empreendimento desta tarefa certamente requer um profissional que, independente de seu instrumental teórico-clínico, possa estar aberto à experiência clínica como um momento em que se articulam o que é da ordem da palavra e do espetáculo. Inspiradas então nas palavras de Foucault, propomos deslocar a clínica de um olhar que prevalece sobre o que é visível para uma clínica na qual o olhar possa comparecer efetivamente como: "Um olhar que escuta e um olhar que fala" (FOUCAULT, 2001, p. 131).

Desse modo, para além de náo reduzir o sujeito a sua queixa ou a seu sintoma, promovendo de imediato uma conduta, trata-se, nesta experiência clínica, de o profissional implicar-se, lançando-se em uma atitude ou postura investigativa. Esta, podemos dizer, é conduzida pelo olhar que escuta, ou seja, um olhar sustentado por diferentes elementos, entre eles uma posiçáo do profissional na relação com o saber, mais precisamente, no fato de ele poder se despir de seus preconceitos, a fim de escutar o que emerge na fala do sujeito, do qual, $a$ priori, nada sabe. Situar-se a partir do não saber radical em relação a ele, sem a ambição de curá-lo, buscar seu bem-estar ou desejar seu bem, a partir de um referencial próprio, é possibilitar um trabalho que favoreça a construção de um novo caminho.

Dito isso, um dos desafios que o profissional de saúde mental encontra na prática institucional é sustentar uma escuta que inclua a subjetividade daquele que sofre, num ambiente que em geral prima por uma prática de caráter normatizador a partir de um saber prévio, muitas vezes vinculado aos ideais de bem e cura (Cf. RINALDI, 2006).

A clínica no ambulatório de saúde mental, como já citada, tem início no acolhimento. Esse primeiro contato, apesar de ainda não se configurar como tratamento em si, já coloca em cena as variáveis em jogo que convocam ao trabalho. Aquele que busca ou que chega ao acolhimento na saúde mental vem com um pedido de ajuda para seu sofrimento. Este pedido comparece através da solicitação de medicação que o alivie, de uma psicoterapia, aconselhamento, entre tantas outras formas, inclusive terceirizada, isto é, sem que o próprio 
sujeito o protagonize. Nesses casos, pode chegar através da demanda parental, da

escola, de outros profissionais/instituiçóes. Na maioria das vezes, identifica-se a premência pela resolutividade do estado no qual o sujeito se encontra. No entanto, se aberto ou desperto para a clínica, o profissional pode buscar estabelecer uma dinâmica marcada pela investigação, em que seu trabalho passará por localizar o sujeito em seu sofrimento, que muitas vezes é apresentado como algo que vem de fora, como se estivesse dissociado de uma trama histórica pessoal. Nesse sentido, a concepção do adoecer psíquico pode ganhar novos contornos e elementos, sobretudo na medida em que se considera a perspectiva de que "Quem adoece e sofre é, antes de tudo, um sujeito [...]” (FIGUEIREDO, 1997, p. 43).

Sendo assim, circunscrevemos uma noção de clínica em saúde mental pautada fundamentalmente em uma atitude desperta para a clínica que favoreça a abertura necessária para que, no decorrer dos encontros, outra dimensão da queixa apareça, uma que singulariza o pedido de ajuda. Por esse ângulo, a escuta é fundamental para melhor traduzir a demanda, e daí colocá-la em movimento de trabalho. Se essa perspectiva não é específica do ambulatório de saúde mental, mas de qualquer experiência clínica deste campo, é preciso destacar que o profissional do ambulatório não pode prescindir dela.

\section{O ambulatório de saúde mental no contexto da expansão das políticas públicas de saúde}

A noção de um despertar para a clínica é trazida neste artigo como um norteador que agrega múltiplos elementos, fundamentais para sustentar o trabalho no campo da saúde mental. Esta noção é correlata a uma determinada posição do profissional em relação ao seu fazer clínico, o que exige deste uma construção e mesmo algum trabalho pessoal interno que lhe permita uma disponibilidade ao outro. Contudo, um grande desafio para a construção deste despertar aparece com os novos desenhos que reorientam a assistência a partir das novas políticas públicas em saúde com o objetivo de expandir a Atenção Primária, através das Clínicas de Família, da Estratégia de Saúde da Família (ESF), dos Núcleos de Apoio a Saúde da Família (NASFs).

A política nacional do Ministério da Saúde tem como diretriz a ampliação do cuidado em saúde no território, ou seja, com base comunitária (Cf. CHIAVERINI, 2011). O município do Rio de Janeiro se alinha a este cenário e vem expandindo 
a cobertura das equipes da ESF, iniciada em 2009, já sendo possível reconhecer o crescente aumento destes dispositivos nas diferentes regióes da cidade (BRASIL, 2012). No que concerne ao campo da saúde mental, as incidências das novas políticas são diversas. Da aproximação que se estabeleceu entre as equipes da ESF e os dispositivos de saúde mental, prioritariamente os CAPS e os Ambulatórios, decorreu um novo arranjo no trabalho e nos fluxos de uma rede de atenção psicossocial que tomou a ESF como mais um recurso para a saúde mental. Essa reorganização visa ao compartilhamento de responsabilidades entre os serviços de saúde mental e os da atenção primária, através de uma lógica que, em oposição à prática do encaminhamento para o especialista, requer a apropriação de um compromisso com o cuidado de uma determinada clientela.

O apoio matricial em saúde mental é o eixo principal que sustenta a parceria deste campo com a atenção primária. Isto vem se desenvolvendo no município do Rio de Janeiro a partir dos CAPS, Ambulatórios e NASFs, sendo possível recolher efeitos positivos do trabalho junto à ESF no espectro da saúde mental, esbarrando, porém, em alguns impasses. O matriciamento em saúde mental, além de oferecer um suporte técnico especializado às equipes da ESF, visa também agir no sentido de proporcionar uma educação permanente (Cf. CHIAVERINI, 2011). Este novo contexto implica mudanças para o ambulatório de saúde mental no que se refere a sua organizaçáo, processo de trabalho, clientela acompanhada, levando-nos a interrogar os critérios que devem ser adotados para a oferta deste dispositivo diante de uma realidade que redesenha a rede de atenção psicossocial. Então, como situar o ambulatório no novo ordenamento? E como fazer valer a noção de um despertar para a clínica na nova realidade em que se entrelaçam diferentes recursos institucionais?

Certamente, já é possível recolher os efeitos do trabalho da ESF no âmbito da saúde mental, sobretudo no que diz respeito aos casos graves, até então sem acesso aos serviços de saúde e sem acompanhamento regular. Um bom exemplo disso sáo os pacientes gravemente comprometidos do ponto de vista psíquico, alguns em situação de cárcere privado, que tiveram sua condição de tratamento viabilizada a partir da inserção da ESF no território, que, além de detectá-los, pôde contar com as parcerias estabelecidas via matriciamento de saúde mental.

Interrogamo-nos, no entanto, quanto a uma série de outras situaçóes que despontam no cotidiano da relaçáo entre ESF e ambulatório de saúde mental, 
posto que o matriciamento não é dado, é uma construção! Um impasse vivenciado

nesse sentido é perpassado pela rotatividade das equipes da ESF, estabelecendo obstáculos para a regularidade do trabalho clínico, incluindo aqui a continuidade dos projetos terapêuticos e os vínculos estabelecidos. Mas talvez a maior delicadeza seja certo consenso que em geral vigora de que a ESF tem como exercer o cuidado sem o apoio matricial a uma clientela considerada menos grave, isto é, os chamados casos leves, aqueles cujos sofrimentos remontam a lutos, situações de violência, medos, tristezas, separações, ansiedades (BRASIL, 2012).

Sabemos que há situaçôes tidas como leves ou moderadas que, se não são bem conduzidas, podem evoluir negativamente, gerando prejuízos importantes para o paciente, que pode passar a um estado de maior comprometimento psíquico. Essa consideração é fundamental e inclui os riscos de prescriçôes abusivas de psicotrópicos como resposta prevalente ao sofrimento, assim como intervenções pontuais que banalizam a escuta clínica, sobretudo levando-se em conta o grande volume de demandas para tratamento, a escassez de recursos humanos e a pressão por soluçóes imediatas tão presente na contemporaneidade.

Como já referido neste artigo, o ambulatório de saúde mental, há pelo menos doze anos, passou a se dedicar a uma clínica que prioriza casos de maior gravidade. Nesse tempo, o ambulatório de psicologia e psiquiatria se deparou com a grande quantidade de pessoas que chegavam a sua porta, mas que, no entanto, não pertenciam ao escopo dos casos graves; estes compunham a grande maioria e eram situaçóes leves ou moderadas. Diante desta demanda, o ambulatório precisou se reinventar no sentido de ampliar as formas de cuidado, como, por exemplo, os atendimentos em grupo e também, pela via do grupo de recepção, introduzir um tempo de escuta, avaliação e trabalho junto a pacientes que, apesar de algum sofrimento, não prioritariamente seriam indicados para um acompanhamento.

Se, por um lado, é importante que os casos leves não sejam psicopatologizados, adentrando necessariamente em tratamentos ambulatoriais; por outro, deve-se estar atento para o modo como se encontra organizada a subjetividade de cada um, ou seja, a maneira pela qual cada um atravessa as diferentes situaçóes ao longo da vida, bem como a que está relacionado o sintoma apresentado. Esse aspecto é singular da clínica, indicando a necessidade de uma análise mais abrangente do caso do que permite supor um conjunto de manifestaçóes sintomatológicas ou mesmo um protocolo de situação de risco. Quanto a isto, questionamos se 
é efetivamente possível de ser conduzido por um não especialista do campo da saúde mental. $\mathrm{Na}$ verdade, é preciso tomar o cuidado de não considerar a gravidade do caso exclusivamente pela sintomatologia e deixar que isso atrapalhe a sua indicação para tratamento e seu direcionamento a expensas da clínica.

Ocorre que, no que diz respeito especificamente aos casos de saúde mental, há uma tensão entre ambulatório e ESF quanto à efetividade dos desdobramentos, considerando-se a condução exclusiva pela ESF, mesmo daqueles casos identificados como leves. Como bem assinala Couto (2003), em meio ao universal e à dureza das políticas que norteiam o campo público para o cuidado de todos, a clínica é justamente o singular e a delicadeza, o tratamento de cada um. Segundo a autora, se pretendemos um trabalho efetivo no campo da saúde mental, é importante operarmos numa tensão viva entre essas duas perspectivas de cujos mandatos nenhuma delas pode ceder. De nossa parte, defendemos a importância de manter viva a tensão entre o universal das políticas e a singularidade da clínica. Essa tensão precisa ser sustentada de modo a não deixar escapar tanto aquilo que precisamente consiste na potência do ambulatório de saúde mental quanto o que abrange os benefícios obtidos com a expansão das políticas de atenção primária via o trabalho da ESF no território.

\section{Considerações finais}

As conquistas alcançadas no campo da saúde mental embaladas pelo movimento da Reforma Psiquiátrica, sem dúvida, foram gigantescas. Além disso, deve-se avaliar igualmente como um avanço as diretrizes mais recentes do Ministério da Saúde, que visam, através da Atenção Primária em Saúde, a uma reorientação do modelo de assistência. Diante desta nova política, entendemos ser importante sublinhar o ambulatório de saúde mental na pauta de discussóes da rede de atenção psicossocial e, através deste trabalho, visamos considerar alguns aspectos que favoreçam reflexóes acerca deste dispositivo, buscando romper o silêncio ou inexpressividade que parece cercá-lo, afirmando que se trata enfim de um dispositivo potente na rede.

Sustentamos que a potência do ambulatório de saúde mental na rede de atenção psicossocial está em prestar assistência em um nível secundário, exercendo uma clínica que singulariza o sujeito nas diferentes modalidades de cuidado ofertadas, e que, especificamente no âmbito psicoterápico, atende a uma determinada 
clientela que lhe é própria e que até pode coincidir com o público adscrito à ESF e ao CAPS, mas que, no entanto, o que encontram no ambulatório lhe é especifico e singular, na medida em que na ESF não há atendimento continuado e especializado ofertado por profissional de saúde mental, e no CAPS, apesar de haver especialistas e a possibilidade deste tratamento, este se volta para um perfil de usuários que demanda intensividade do cuidado. $\mathrm{O}$ ambulatório é, assim, o local onde um trabalho clínico e psicoterápico, porém não intensivo, pode ser feito com uma clientela que dele pode se beneficiar por um período de tempo.

Certamente, a despeito do dispositivo, a dimensão clínica que considera a singularidade potencializa o sujeito à medida que possibilita sua mudança de posição em relação ao que o faz sofrer. Isto torna o trabalho profícuo em qualquer equipamento de saúde mental. No ambulatório, então, não podemos dizer que há uma clínica específica em função do dispositivo ambulatório, mas que nele é possível desempenhar uma clínica de fato significativamente interessante à rede de atenção psicossocial por abarcar de modo potente certo público. Acreditamos que nesses moldes a clínica traz um vigor ao trabalho nas distintas abordagens de atendimento à populaçáo, incluindo aí sua potência em açóes que rompem as paredes institucionais, estendendo o trabalho ao território, sem o qual o ambulatório pode ficar engessado apenas nos moldes do atendimento em consultório.

As questôes que levantamos fomentam assim discussôes que têm como objetivo colocar e manter em jogo diferentes elementos necessários e favoráveis ao campo da saúde mental, num contexto atual de trabalho, no qual ambulatório e ESF encontram-se tensionadamente entrelaçados. Nesse sentido, localizamos a ESF junto à rede de saúde mental como um direcionamento que, na capilarizaçáo do cuidado que promove no território, pode empreender a desinstitucionalização na sua radicalidade. Contudo, chamamos a atenção para o fato de que, ao imprimir esse trabalho comunitário, não deve ser perdida de vista a dimensão clínica, perspectiva que efetivamente sustenta e sedimenta a desinstitucionalização junto aos ditames da atenção psicossocial preconizados pela Reforma Psiquiátrica. Esta é uma conquista já arduamente alcançada nesse campo.

Ao destacar a importância de um despertar para a clínica em tempos nos quais novos desenhos são implantados na assistência, com consequências para o trabalho no ambulatório de saúde mental, apontamos e creditamos finalmente este dispositivo como um recurso fundamental na rede de atenção psicossocial. E dele não podemos abrir mão! 


\section{Referências}

ALVES, D.S.; GULJOR, A.P. O cuidado em saúde mental. In: PINHEIRO, R.; ARAUJO DE MATOS, R. (Orgs.). Cuidado: as fronteiras da integralidade. Rio de Janeiro: Cepesc, 2005, p. 221-240.

AMARANTE, P. Saúde mental e atenção psicossocial. Rio de Janeiro: Fiocruz, 2007.

BRASIL. Secretaria Municipal de Saúde do Rio de Janeiro. Coordenadoria de Saúde Mental. Recomendaçóes sobre atendimento em Saúde Mental na Rede Básica. Rio de Janeiro: SMS-RJ, 2005.

. Secretaria Municipal de Saúde e Defesa Civil do Rio de Janeiro. Sobre o início do matriciamento em saúde mental na cidade do Rio de Janeiro: reflexôes, relatos e recomendaçóes. Rio de Janeiro: SMSDC-RJ, 2012.

Ministério da Saúde. Portaria GM 3088, de 23 de dezembro de 2011. Brasília: Ministério da Saúde, 2011.

CHIAVERINI, D.H. (Org.). Guia prático de matriciamento em saúde mental. Ministério da Saúde: Centro de Estudos e Pesquisa em Saúde Coletiva, 2011.

COUTO, M.C.V. Trilhando novos caminhos: a política pública de saúde mental para crianças e adolescentes. In: GUERRA, A.M.A.; LIMA, N.L. (Orgs.). A clínica de crianças com transtornos no desenvolvimento. Uma contribuição no campo da Psicanálise e da Saúde Mental. Belo Horizonte: Autêntica, 2003, p. 191-198.

DORON, R.; PAROT, F. (Orgs.). Psicologia Clínica. Dicionário de Psicologia. São Paulo: Ática, 1998, p. 144-145, v. I.

ELIA, L. A rede da atenção na saúde mental - articulaçôes entre CAPS e ambulatórios. In: BRASIL. MINISTÉRIO DA SAÚDE. Caminhos para uma politica de saúde mental infantojuvenil. 2005, p. 49-61.

ERLICH, H.; ALBERTI, S. O sujeito entre psicanálise e ciência. Psicologia em Revista. Belo Horizonte, v. 14, n. 2, p. 47-63, 2008.

FÉDIDA, P. Dos beneficios da depressão: elogio da psicoterapia. São Paulo: Escuta, 2009.

FIGUEIREDO, A.C. Vastas confusóes e atendimentos imperfeitos: a clínica psicanalítica no ambulatório público. Rio de Janeiro: Relume Dumará, 1997.

FOUCAULT, M. O nascimento da clínica. 5. ed. Rio de Janeiro: Forense Universitária, 2001.

ORGANIZAÇÃO MUNDIAL DA SAÚDE. Classificação de transtornos mentais e de comportamento da CID-10. Porto Alegre: Artes Médicas, 1993.

PITTA, A. Tecendo uma teia de cuidados em saúde mental. In: VENANCIO, A.T.; CAVALCANTI, M.T. (Orgs.). Saúde mental: campo, saberes e discurso. Rio de Janeiro: IPUB/CUCA, 2001, p. 277-282. 
RINALDI, D. Entre o sujeito e o cidadão: psicanálise ou psicoterapia no campo da saúde mental? In: ALBERTI, S.; FIGUEIREDO, A.C. (Orgs.). Psicanálise e saúde mental: uma aposta. Rio de Janeiro: Companhia de Freud, 2006.

ROTELLI, F. A instituição inventada. In: NICACIO, F. (Org.). Desinstitucionalização. São Paulo: Hucitec, 1990, p. 89-99.

SCMIDT, M.B.; FIGUEIREDO, A.C. Acesso, acolhimento e acompanhamento: três desafios para o cotidiano da clínica em saúde mental. Revista Latinoamericana de Psicopatologia Fundamental. São Paulo, v. 12, n. 1, p. 130-140, 2009.

SILVA FILHO, J.F. O ambulatório e a psiquiatria. Cadernos IPUB. Rio de Janeiro, n. 17, p. 17-20, 2000.

\section{Notas}

${ }^{1}$ Cria e regulamenta o funcionamento dos serviços residenciais terapêuticos (SRTs) em Saúde Mental.

${ }^{2}$ Amplia a abrangência dos serviços substitutivos de atenção diária: os Centros de Atenção Psicossocial-CAPS, com portes diferenciados e com especificidade para a clientela infantojuvenil e para dependência de álcool e outras drogas.

${ }^{3}$ Conhecida como Lei Paulo Delgado, dispóe sobre a proteção e os direitos das pessoas portadoras de transtornos mentais e redireciona o modelo assistencial em saúde mental, privilegiando o tratamento em serviços territoriais.

${ }^{4}$ Chamada Programa de Volta para Casa - PVC, institui o auxilio-reabilitação psicossocial para portadores de transtorno mental egressos de internaçôes de longa permanência.

${ }^{5}$ I. Damous e H. Erlich participaram igualmente da pesquisa, discussão sobre a teoria e experiência prática no campo e redação do artigo. 


\section{Abstract}

\section{The mental health clinic in the psychosocial care network: reflections on the clinic and the expansion of primary care policies}

The Psychiatric Reform movement and the recent guidelines in the field of Primary Health Care redirect the model of mental health care in Brazil and make great achievements possible. In this context, this article addresses the mental health outpatient clinic with the objective of affirming it as a fundamental and potent device in the psychosocial care network. Taking the clinic as the main axis, the discussion carried out mainly follows theoretical contributions of reference on the foundations of the field of psychosocial care, public health and mental health policies, besides considering the theoretical-clinical contributions of authors crossed by psychoanalysis and inserted in the field of mental health, as well as the long experience of the authors in this field. The clinical dimension regarding the outpatient clinic is highlighted, with the strong power of this device being attributed to a certain way of exercising it, to the different modalities offered, to the organization of services and to the reception and follow-up of a particular clientele. Finally, it is argued that, from an attitude that awakens to the clinic, a powerful mental health clinic in a psychosocial care network effectively promotes the desired work towards the territory and, therefore, for the true deinstitutionalization.

> Keywords: mental health; psychosocial care; outpatient clinic; clinic. 